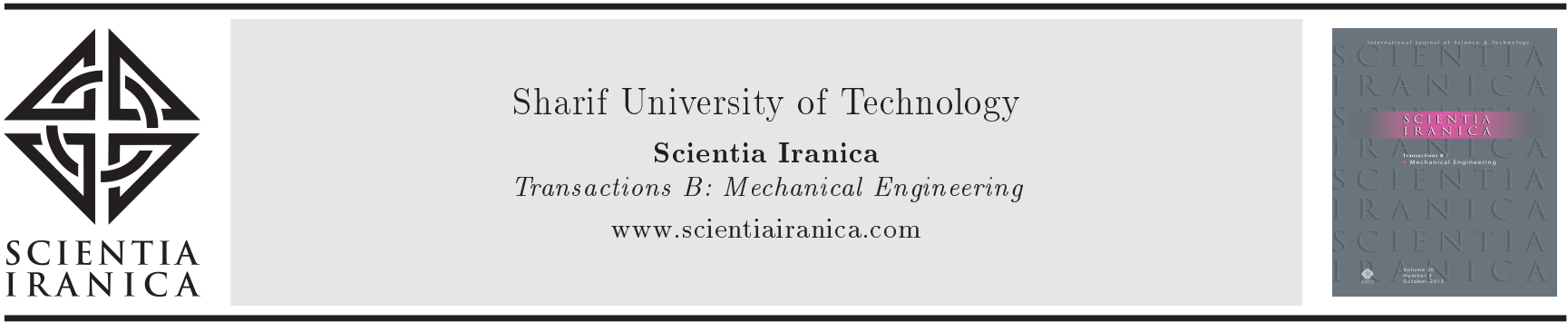

\title{
Modeling and optimizing of photovoltaic-wind-diesel hybrid systems for electrification of remote villages in Iran
}

\author{
M. Sedghi and S. Kazemzadeh Hannani* \\ School of Mechanical Engineering, Sharif University of Technology, Tehran, Iran.
}

Received 5 March 2014; received in revised form 27 July 2015; accepted 15 September 2015

\author{
KEYWORDS \\ Photovoltaic; \\ Wind turbine; \\ Diesel generator; \\ Economic \\ optimization; \\ Iranian villages.
}

\begin{abstract}
The main objective of this work is to provide an electric supply to remote Iranian villages that have no access to electricity grid using a stand-alone hybrid system. The hybrid systems considered in this study consist of a photovoltaic array, wind turbine, diesel generator, and battery storage. Measured wind speed data was used for a wind turbine energy production model. The hybrid system optimized the electricity supply of villages with 6, 14, 20, 40, and 60 households in Bojnord, Moorchekhort, Kish, Langroud, Khash, and Meshkinshahr. The main purpose of this optimization is to find an economical system configuration that is able to fulfill the energy requirements of a given load distribution while considering Iran's current economy and cost. The optimized results for studied cases have been analyzed and implementation feasibility is discussed.
\end{abstract}

(C) 2016 Sharif University of Technology. All rights reserved.

\section{Introduction}

An estimated more than 1 billion people in the world have no access to electricity [1,2]. More than $85 \%$ of people without access to electricity live in rural areas [2]. There are many factors contributing to the poor distribution of electrical resources, such as harsh terrain and the isolation of many rural villages.

An autonomous power system providing energy independence to remote consumers is one of the most interesting solutions to similar electrification problems. In these regions, the choice of diesel power generation has traditionally been considered as the most economical and reliable alternative. However, the volatile prices of fossil fuels and the very high maintenance cost of diesel generators coupled with environmental and climate change concerns make this option unsustainable [3].

*. Corresponding author. Tel.: +982166165508 E-mail address: hannani@sharif.edu (S. Kazemzadeh Hannani)
Alternative energy resources such as solar and wind have attracted energy sectors to generate power, although the common drawback of solar and wind energy is its unpredictable nature and dependence on weather and climatic changes. Stand-alone photovoltaic $(\mathrm{PV})$ or wind energy systems do not produce usable energy for a considerable portion of time during the year [4]. For these systems, a battery is used to store electrical energy. At present, the cost of batteries during the lifetime of a wind generator and PV module has made up a fairly large part of the total cost of PV or wind generating systems [5]. To help alleviate this problem, some researchers have proposed other energy storage methods, such as compressed air energy and hydrogen storage $[6,7]$.

The term hybrid system is used to describe any energy system composed of more than one type of generator. The use of different energy sources allows the system to improve efficiency and reliability of the energy supply and reduce the energy storage requirements when compared to systems comprising only one single renewable energy source [8]. 
Hybrid PV-diesel [9-13], wind-diesel [14-16], PVwind [17-21], or PV-wind-diesel [22-27] systems with batteries storage have been widely studied in the literature. Hybrid systems are mainly recognized for remote area power applications and are currently a cost-effective option where extension of grid supply is prohibitively expensive. Although the cost and technological development of hybrid systems in recent years has been encouraging, they are still an expensive source of power [28].

The design of hybrid systems is a very complex problem containing a high number of parameters; therefore, the classical techniques of design may produce unsatisfactory results [29]. In some studies, the program HOMER is used for determining configuration of the hybrid system $[13,18,20,30]$. The program HOMER, which optimizes hybrid systems, uses an enumerative technique in searching for the optimal design. The enumerative technique assures finding the best possible solution, but it may require an excessively high CPU time. In recent years, optimization algorithms have received increasing attention by the research community as well as industry. These algorithms have been applied to many problems, getting very good results where other techniques have failed.

The main purpose of this study is electric supply to remote Iranian villages that have no access to the electricity grid using a stand-alone PV-wind-diesel system with batteries storage (Figure 1). The system components are modeled and verified with various measured data. After modeling of the system, the PV power, wind turbine power, diesel generator power, and battery storage capacity are selected as design parameters (decision variables) and this equipment is optimized by minimizing the annualized life cycle cost. Since the cost of hybrid systems depends on

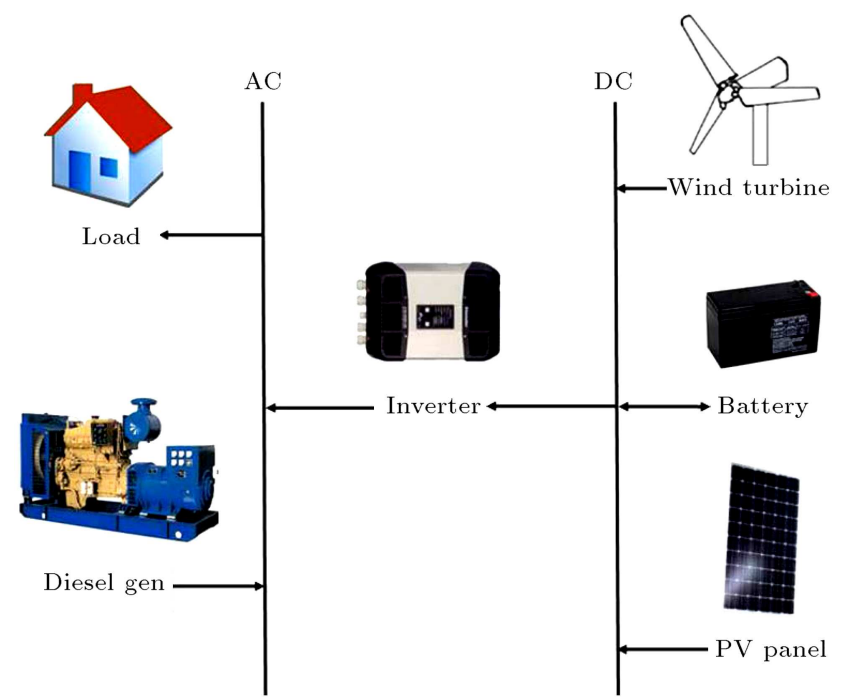

Figure 1. PV-wind-diesel with battery storage hybrid system. the climatic conditions and the load energy demand, in this study, six different climatic regions in Iran are considered and the hybrid systems are optimized to provide an electricity supply in villages with 60,40 , 20,14 , and 6 households.

\section{Mathematical model of the hybrid system}

\section{1. $P V$ generator}

The output power of a PV generator $\left(P_{p v}\right)$ with an open circuit voltage $V_{o c \_r e a l}$ and short circuit current $I_{\text {sc_real }}$ under real operating condition is calculated by the following equation [31]:

$$
P_{p v}=f f .\left(V_{\text {oc_real }} \cdot I_{s c \_r e a l}\right) \text {, }
$$

where $f f$ is the fill factor given by:

$$
f f=\frac{P_{\max }}{I_{s c} \cdot V_{o c}}
$$

where $P_{\max }$ represents the maximum output power of a $\mathrm{PV}$ generator under laboratory condition; $V_{o c}$ is the open circuit voltage of $\mathrm{PV}$ under laboratory condition; and $I_{s c}$ is the $\mathrm{PV}$ short circuit current under laboratory condition. The values of $P_{\max }, V_{o c}$, and $I_{s c}$ are obtained from PV module manufacturers.

$V_{\text {oc_real }}$ and $I_{\text {sc_real }}$ can be calculated as follows:

$$
\begin{aligned}
& V_{o c_{-} \text {real }}=V_{o c}+f_{V_{o c-T}} \cdot T_{c}, \\
& I_{s c_{-} \text {real }}=\left(I_{s c}+f_{I_{s c_{-} T}} \cdot\left(T_{c}-T_{s t d}\right)\right) \cdot\left(\frac{G}{G_{s t d}}\right) G,
\end{aligned}
$$

where $f_{V o c_{-} T}$ and $f_{I s c_{-} T}$ are temperature correction coefficients of current and voltage, respectively. $T_{s t d}\left({ }^{\circ} \mathrm{C}\right)$ and $G_{s t d}\left(\mathrm{w} / \mathrm{m}^{2}\right)$ are temperature and solar radiation in standard conditions, respectively, and $T_{c}\left({ }^{\circ} \mathrm{C}\right)$ is the surface temperature of the PV panel. The parameters $f_{V o c_{-} T}, f_{I s_{-} T}, T_{s t d}$, and $G_{s t d}$ depend on the type of the used module and are obtained from PV module manufactures. $G\left(\mathrm{w} / \mathrm{m}^{2}\right)$ is the solar radiation on the surface of the PV. In this study, the mathematical models presented in $[32,33]$ are used in calculating solar radiation.

SGP Co solar laboratory in Moorchekhort measures solar radiation. The maximum error between measured and modeled solar radiations in 2012 was $8 \%$. Figure 2 depicts the calculated and measured solar radiations on June 7,2013 , for a slope equal to $39^{\circ}$ in Moorchekhort.

\subsection{Wind turbine}

The power output of a wind turbine is proportional to air density, the swept area of the turbine blades, the cube of the wind speed, and the power coefficient. The non-dimensional power coefficient represents the fraction of power extracted from the power in the wind 


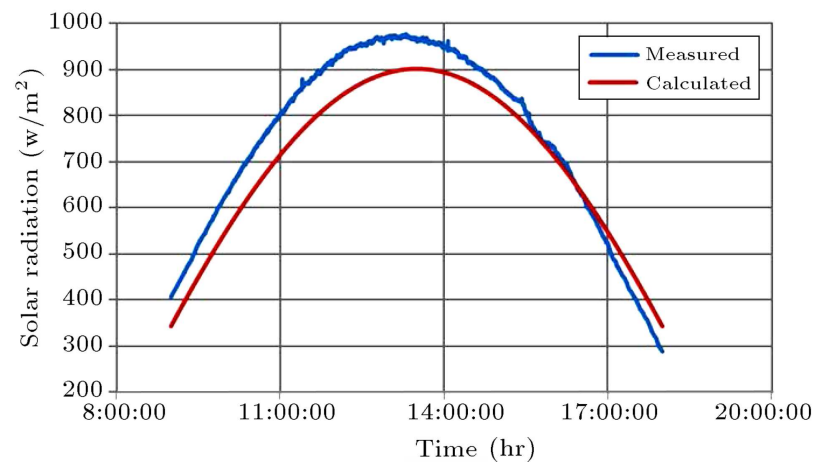

Figure 2. The difference between calculated and measured solar radiations on June 7, 2013, in Moorchekhort.

by a practical wind turbine. The power coefficient is not constant and varies with turbine blade parameters, the wind speed, and the rotational speed of the turbine.

The power curve of the wind turbine is estimated by means of an averaged manufacturer's power output curve instead of the wind's kinetic energy and the power coefficient. Wind turbine manufacturers provide turbine power curves at different wind speeds. Each wind turbine has its own characteristic known as wind speed power curve. The shape of this curve is influenced by the area of blades, number of blades, blade shape, optimum tip speed ratio, rotation speed, cut-in and cut-out wind speeds, rated speed, and generator efficiencies. The power output of a wind turbine varies with wind speed and wind turbine power curve. If the power curve of the turbine is not available, the following equation can be used to simulate the power output of a wind turbine as a function of wind speed [34]:

$$
P_{\text {turbine }}= \begin{cases}0 & v<v_{c} \\ P_{e r} \frac{v^{m}-v_{c}^{m}}{v_{r}^{m}-v_{c}^{m}} & v_{c}<v<v_{r} \\ P_{e r} & v_{r}<v<v_{f} \\ 0 & v>v_{f}\end{cases}
$$

where $P_{e r}$ is the wind turbine rated power, $v(\mathrm{~m} / \mathrm{s})$ is wind speed, $v_{c}(\mathrm{~m} / \mathrm{s})$ is the cut-in wind speed, $v_{r}(\mathrm{~m} / \mathrm{s})$ is the rated wind speed, and $v_{f}(\mathrm{~m} / \mathrm{s})$ is the cut-out wind speed. Setting $m=2$ is often sufficiently accurate for analysis of wind power systems [35]. As shown in Eq. (5), the wind turbine will generate power only when the actual wind speed exceeds a cut-in velocity. If the wind speed exceeds the cut-out value, the wind turbine generator stops running to prevent structural damage. In this study, $v_{c}, v_{r}$, and $v_{f}$ were set to 3,9 , and $20(\mathrm{~m} / \mathrm{s})$, respectively.

The estimation of the wind resource at the hub height of a wind turbine is one of the primary goals of site assessment. Since in a majority of cities the wind speed is measured at lower heights, the power law model is applied to estimate the wind speed at higher heights. The wind power law model is described by the following equation [34]:

$$
\frac{v_{2}}{v_{1}}=\left(\frac{Z_{2}}{Z_{1}}\right)^{\alpha_{z_{2}-z_{1}}}
$$

where $v_{2}$ and $v_{1}$ denote the wind speeds at different heights of $Z_{2}$ and $Z_{1}$, respectively, and $\alpha_{Z_{2}-Z_{1}}$ is the shear coefficient. The value of $\alpha=1 / 7$ is usually taken when there is no specific site data. However, in practice, the shear coefficient, $\alpha$, is a highly variable quantity, and it has been ascertained that $\alpha$ varies with many parameters such as height, time of day, season, nature of the terrain, wind speed, temperature, and various thermal and mechanical mixing parameters [34].

Iran's Renewable Energy Organization has installed meteorological towers in several places for the feasibility study of wind power production. The wind speed data is collected at 10, 30, and $40 \mathrm{~m}$ heights every 10 minutes [36]. In this paper, since the wind speed at 10,30 , and $40 \mathrm{~m}$ heights is measured by weather station anemometers, the hourly shear coefficient, $\alpha$, in the months of the year is calculated via Eq. (6), and the wind speed at different heights is estimated by the power law model. Iran's Renewable Energy Organization has also installed wind turbines with $660 \mathrm{kw}$ rated capacity in a number of places in Iran which report yearly energy production.

For validation of the wind turbine model, Zabol, Tabriz, and Binaloud wind farm sites have been selected. Since the wind speed data at two heights was available, we used the wind turbine model to estimate the wind speed at hub height and calculate the annual wind turbine energy production. Figure 3 shows the difference between actual and calculated annual wind turbine energy production. In these cities, the maximum error between measured and calculated wind turbine energy production is less than $7 \%$.

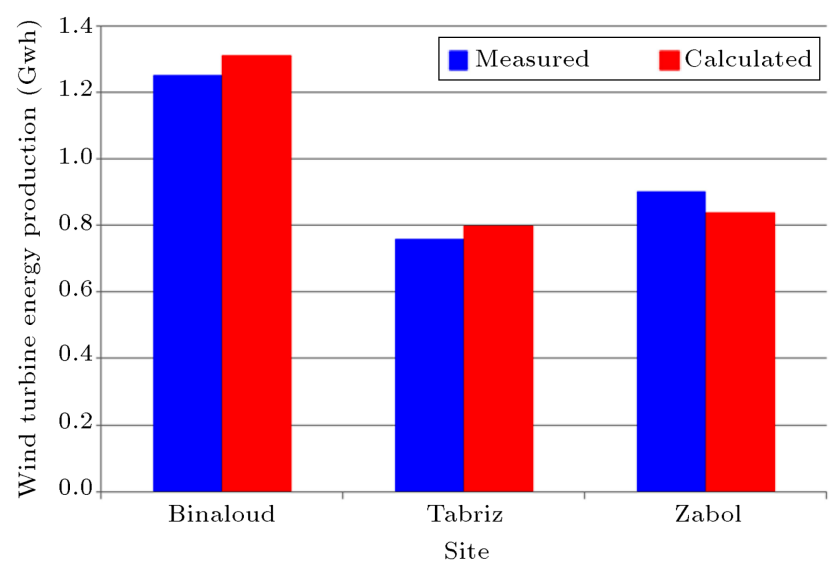

Figure 3. The difference between actual and calculated annual wind turbine energy production. 


\subsection{Diesel generator}

The main purpose of this study is electric supply to remote Iranian villages that have no access to the electricity grid. These remote villages in Iran are not connected to the natural gas lines. In these villages, the generator fuel should be stored in the village. Storing large quantities of natural gas or gasoline is hazardous. Gasoil is the best option for this problem and in this study, diesel generator was selected as a backup system.

A diesel generator is usually included in a hybrid system to supply power during extended periods of low solar radiation and to supply peak power in order to reduce the array size as well as the battery bank.

When the generated energy by the renewable sources is not sufficient to cover the load demands and the battery is also discharged to its minimum value, the diesel generator is switched on, and in addition to the generated energy by the renewable sources, it supplies the load and charges the batteries. The hybrid system still remains in this mode of operation until the batteries are recharged to their full capacity.

Diesel engine characteristics, such as efficiency, are a function of partial load (part load) which is defined as the percentage of nominal load [37]. In practice, the specific (diesel) fuel consumption (kWh/l) is never in exact proportion to the load and decreases non-linearly with reducing load. The fuel consumption of diesel generators can be described by [9]:

$$
F_{\text {diesel }}=a \cdot P_{\text {rated }}+b \cdot P_{D G},
$$

where $F_{\text {diesel }}(1)$ is the fuel consumption, $P_{\text {rated }}(\mathrm{kW})$ is rated power of the generator, and $P_{D G}(\mathrm{~kW})$ is output power of the diesel generator. $a=0.08415(\mathrm{l} / \mathrm{kWh})$ and $b=0.2661(\mathrm{l} / \mathrm{kWh})$ are the fuel curve coefficients.

In this paper, the minimum output power of a diesel generator (minimum partial load) is assumed to be $25 \%$ of the rated power of the diesel generator. The diesel generator lifespan is considered as 20,000 hours.

\subsection{Battery}

In this study, a lead-acid battery is used to store electrical energy. This battery has a high initial cost and is a low-lifespan battery, leading to heavy costs imposed on the system.

When the total output of generators $\left(E_{T}\right)$ is greater than the energy demand $\left(E_{L}\right)$, the battery bank is in a charging state. The charge quantity of the battery bank $\left(E_{B}\right)$ at time $t$ can be described by [5]:

$$
E_{B}(t)=E_{B}(t-1)+\left(E_{T}-E_{L} / \eta_{i n v}\right) \cdot \eta_{B},
$$

where $E_{B}(t-1)$ is the charge quantities of the battery bank at time $t-1 . \eta_{B}$ and $\eta_{i n v}$ are the efficiency of the inverter and charge efficiency of the battery bank, respectively. On the other hand, in the discharging state, the charge quantity of the battery bank at the time $t$ can be expressed as [5]:

$$
E_{B}(t)=E_{B}(t-1)+\left(E_{L} / \eta_{i n v}-E_{T}\right) .
$$

At any time, the charge quantity of the battery bank is subject to the following constraints:

$$
E_{B, \min } \leq E_{B}(t) \leq E_{B, \max }
$$

The maximum charge quantity of the battery bank $\left(E_{B, \max }\right)$ takes the value of the nominal capacity of the battery bank $\left(C_{B}\right) . E_{B, \min }$ is the minimum charge quantity of the battery bank and is given by [5]:

$$
E_{B, \min }=(1-D O D) \cdot C_{B}
$$

where $D O D$ is the maximum depth of discharge and in this study, DOD takes the value of $80 \%$.

When the energy generated by the hybrid system is greater than load and the battery bank is in maximum charge state, the surplus energy is consumed by the dump load.

The lifetime of a lead-acid battery is defined based on the frequency of charging and discharging, and depends on DOD. In this study, Eq. (12) is used to estimate the lifespan of lead-acid battery [38]:

$$
\begin{aligned}
\text { Life cycle }= & 1380.3+6833.5 \exp (-8.750 D O D) \\
& +6746 \exp (-6.216 D O D) .
\end{aligned}
$$

\subsection{Charge controller}

In nearly all systems with battery storage, a charge controller is an essential component to protect the battery against deep discharge and excessive overcharge. The controller should be adjustable to ensure optimal battery system performance under various charging, discharging, and temperature conditions.

\subsection{Inverter}

Inasmuch as not all appliances are available as smallDC-voltage devices (particularly appliances with powerful motors, such as washing machines and power tools), an inverter is often used for stand-alone systems to convert DC to AC current.

The inverter efficiency $\left(\eta_{i n v}\right)$ depends on the inverter output power $\left(P_{\text {out,inv }}\right)$ and rated power $\left(P_{\text {rated,inv }}\right)$. This can be described as [39]:

$$
\eta_{i n v}=\frac{\rho}{\rho+0.0415+0.0437 \rho^{2}},
$$

where $\rho$ is the reduced power and is defined as:

$$
\rho=\frac{P_{\text {out }, \text { inv }}}{P_{\text {rated }, i n v}} .
$$




\subsection{Economic model}

The Life Cycle Cost (LCC) of a hybrid system consists of the initial capital investment $\left(C_{i}\right)$, the present value of maintenance costs $\left(P W_{m}\right)$, the present value of hybrid system components replacement cost ( $\left.P W_{\text {replace }}\right)$, and the present value of diesel generator fuel consumption $\left(P W_{\text {fuel }}\right)[40]$ :

$$
\mathrm{LCC}=C_{i}+P W_{m}+P W_{\text {replace }}+P W_{\text {fuel }} .
$$

The initial capital investment, $C_{i}$, is the sum of the investments of each part of the hybrid system, i.e. PV array, wind turbines, diesel generators, inverter, storage batteries, electronic controller, transportation, installation, etc.

$P W_{m}, P W_{\text {replace }}$, and $P W_{\text {fuel }}$ are calculated as follows [40]:

$$
\begin{aligned}
& P W_{m}=C_{m} P a, \\
& P W_{\text {fuel }}=C_{\text {fuel }} P a,
\end{aligned}
$$

where $C_{m}$ and $C_{\text {fuel }}$ are the maintenance cost and the fuel consumption cost in the first year, respectively. In the above equation, $P a$ is expressed as [40]:

$$
P a=\left(\frac{1-i}{d-i}\right)\left(1-\left(\frac{1+i}{1+d}\right)^{N}\right),
$$

where $i$ and $d$ are the inflation rate and market interest rate, respectively, and $N$ is lifetime of the hybrid system (25 years).

The present value of hybrid system components replacement cost $\left(P W_{\text {replace }}\right)$ in Eq. (15) is computed as [8]:

$$
P W_{\text {replace }}=C_{\text {replace }} \sum_{a=1}^{m}\left(\frac{1+i}{1+i_{f}}\right)^{n},
$$

where $C_{\text {replace }}$ is the component cost in the first year, $n$ is lifetime of the component, and $m$ is the number of replacements in lifetime of the hybrid system $(N)$.

Levelized Cost Of Energy (COE) is the average cost per kilowatt hour $(\$ / \mathrm{kWh})$ of useful electrical energy produced by the system. It is calculated as follows [28]:

$$
C O E=\frac{A L C C}{E_{\text {total }}},
$$

where $E_{\text {total }}$ is the useful energy produced by the system. $A L C C$ is the annualized life cycle cost of the system and can be calculated as follow [40]:

$$
A L C C=\frac{L C C}{P a} .
$$

The average inflation rate and market interest rate
Table 1. The initial price of hybrid system components in Iranian markets.

\begin{tabular}{ll}
\hline \multicolumn{1}{c}{ Item } & \multicolumn{1}{c}{ cost } \\
\hline Wind turbine $^{\mathrm{a}}$ & $1000-3000(\$ / \mathrm{kw})$ \\
PV & $2150(\$ / \mathrm{Kw})$ \\
Diesel generator & a \\
Lead-acid battery & $1.3(\$ / \mathrm{Ah})$ \\
\hline a Due to the rated power and manufacture, \\
the real price is determined.
\end{tabular}

in the recent 10 years in Iran are $16 \%$ and $13.9 \%$, respectively.

The initial prices of hybrid system components are given in Table 1 . These prices were collected from Iranian markets in 2013. The diesel price in Iran is $0.14(\$ / 1)$. In this study, the maintenance cost is considered as $3 \%$ of the price of components.

\section{Evolutionary algorithm}

In this study, the genetic algorithm and particle swarm optimization algorithm search for configurations of hybrid system in order to minimize the life cycle cost of the system.

\subsection{Genetic algorithm}

Genetic algorithm is proposed as an appropriate numerical method for solving global optimization. A genetic algorithm scope is very extensive due to very high flexibility in terms of modeling of complex problems and no need for special mathematical conditions such as continuity and differentiability. Genetic Algorithms (GAs) are one of the subsets of evolutionary computations and have held a direct relation with artificial intelligence topic. GAs can be called a global search method that imitates the natural laws of biological evolution. In this algorithm, during the regeneration stage, the genetic operators are used. After this operators influence on a population, the next generation is produced. The operators of selection, crossover, and mutation are most commonly used in genetic algorithms. The integer-based uniform crossover operator takes two parents specified uniquely and exchanges its every corresponding binary bit number at probability $0<P_{c} \leq 1$. Following crossover, the mutation operator makes change in each binary bit at probability $0<P_{m}<0.5$.

In this study, the genetic algorithm optimization was performed for 150 generations using a search population size of $M=100$ individuals, crossover probability of $p_{c}=0.9$, gene mutation probability of $p_{m}=0.035$, and controlled elitism value of $c=0.1$.

\subsection{Particle swarm optimization algorithm}

Particle Swarm Optimization (PSO) algorithm was proposed first by Kennedy and Eberhart in 1996 [41] 
as a non-deterministic search method for optimization. It has been inspired by the mass movement of birds looking for food. In PSO, each bird is a solution to the problem of which the current position, according to updated velocity, will change to the next position. Like evolutionary algorithms, PSO is also a population based heuristic, where the population of the potential solutions is called a swarm and each individual solution within the swarm is called a particle [42].

There is a random parameter, $r$, between 0 and 1 , in the update formula of velocity because of good coverage of the issue and avoidance of exposure to local optimal point. Three values of current motion, particle own memory, and swarm influence with three weighing factors, $w, c_{1}$, and $c_{2}$, lead to a new particle velocity vector (see Eq. (22)):

$$
\begin{aligned}
& v_{k+1}^{i}=w_{k} v_{k}^{i}+c_{1} \operatorname{rand}\left(p^{i}-x_{k}^{i}\right)+c_{2} \operatorname{rand}\left(p_{k}^{g}-x_{k}^{i}\right), \\
& w_{k}=W_{0}\left(\frac{k_{\max }-k}{k_{\max }}\right),
\end{aligned}
$$

where $k$ represents each iteration, $i$ is the $i$ th particle in the population, and $k_{\max }$ is maximum iteration. The term $p_{k}^{g}$ specifies the best global solution obtained by the swarm, and $p^{i}$ is the best position of each particle over time.

The last step in each of the iterations is to update position of the bird by using velocity vector as follows [41]:

$$
x_{k+1}^{i}=x_{k}^{i}+v_{k+1}^{i} .
$$

It is iterated in three stages, including updating velocity, position, and fitness calculation, until the convergence criterion is specified.

In this study, the PSO is performed for 200 iterations, using 100 particles, $W_{0}=1$, and $c_{1}=c_{2}=$ 2. The PSO was run 4 times for each case and the best results are presented here.

\subsection{Objective function and constraints}

In this study, the objective function of the optimum design problem is minimization of the Annualized Life Cycle Cost (ALCC).

The design parameters at any time should satisfy the following constraints:

$$
\begin{aligned}
& P_{p v}+P_{\text {turbine }}+P_{b a t t}+P_{D G} \geq P_{\text {local }}+P_{\text {loss }}, \\
& P_{D G}>\lambda \times P_{D G_{\text {rated }}} \\
& E_{B, \min } \leq E_{B}(t) \leq E_{B, \max }
\end{aligned}
$$

where $P_{p v}$ is the output power of photovoltaic panels, $P_{\text {turbine }}$ the output power of wind turbine, $P_{D G}$ the output power of diesel generator, $P_{D G_{-} \text {rated the rated }}$ power of diesel generator, $P_{b a t t}$ the output power of the batteries, $P_{\text {Load }}$ the load demand, $P_{\text {loss }}$ the aggregated system power losses, and $\lambda$ the minimum load factor of diesel generator which is set to $25 \%$.

\section{Result and discussion}

\subsection{Case study}

In this study, six regions of Iran with different climates have been considered (Figure 4 ). The location information is summarized in Table 2 .

Due to the community lifestyle, the residential hourly load profile varies. The load profile adopted in this research for Iranian households is represented in Figure 5. As shown in this figure, two different load profiles have been considered for "hot seasons" and "cold seasons". Since electric air conditioning systems are needed for hot seasons, the electrical load in these seasons is variable.

Since the population of remote Iranian villages

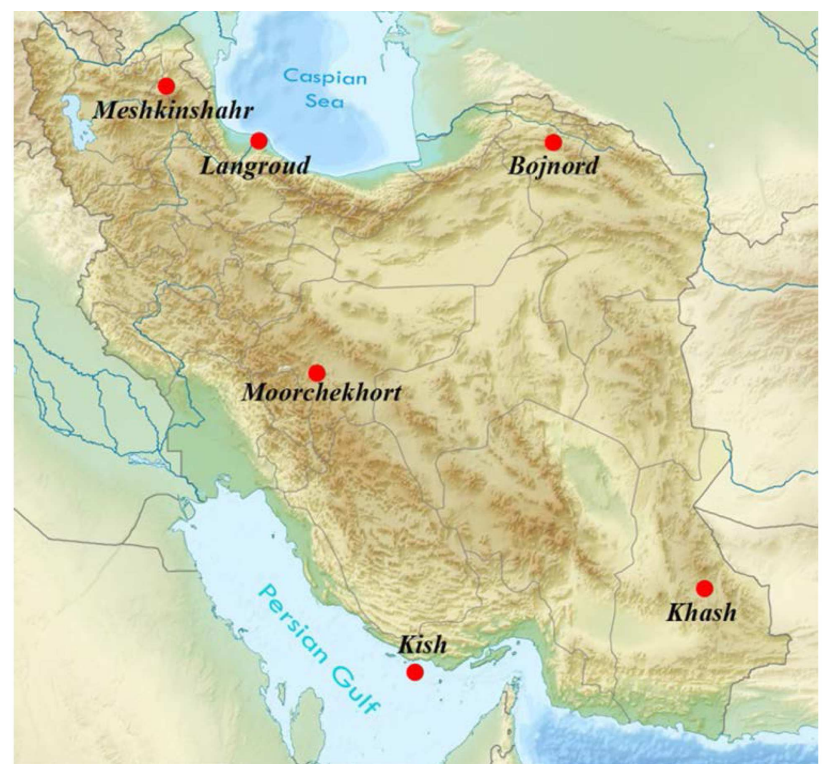

Figure 4. Locations of the cities under study on Iran map.

Table 2. Summary of regions information.

\begin{tabular}{lccc}
\hline \multicolumn{1}{c}{ City name } & $\begin{array}{c}\text { Altitude } \\
(\mathbf{m})\end{array}$ & $\begin{array}{c}\text { Latitude } \\
\text { (degrees) }\end{array}$ & $\begin{array}{c}\text { Longitude } \\
\text { (degrees) }\end{array}$ \\
\hline Khash & 1400 & $28.2^{\circ} \mathrm{N}$ & $61.2^{\circ} \mathrm{E}$ \\
Kish & 10 & $26.3^{\circ} \mathrm{N}$ & $53.5^{\circ} \mathrm{E}$ \\
Langroud & 25 & $37.1^{\circ} \mathrm{N}$ & $50.1^{\circ} \mathrm{E}$ \\
Meshkinshahr & 1394 & $38.3^{\circ} \mathrm{N}$ & $47.6^{\circ} \mathrm{E}$ \\
Moorchekhort & 1570 & $31.8^{\circ} \mathrm{N}$ & $51.6^{\circ} \mathrm{E}$ \\
Bojnord & 1070 & $37.2^{\circ} \mathrm{N}$ & $57.2 \mathrm{E}^{\circ}$ \\
\hline
\end{tabular}




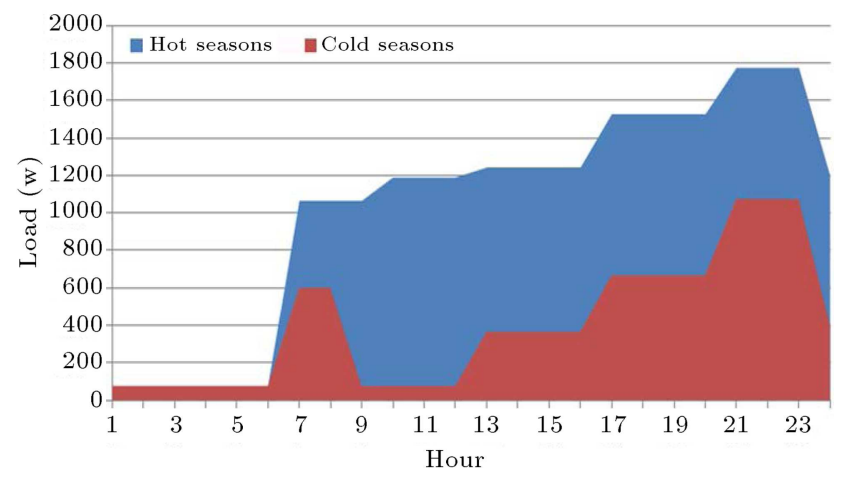

Figure 5. Hourly demanded power of household in a day.

without grid connection is less than 60 families, the hybrid systems are optimized to supply electricity in villages with $60,40,20,14$, and 6 households.

\subsection{Hybrid system configuration}

In this paper, genetic algorithm and particle swarm optimization algorithm are adopted in detecting the PV panel power, wind turbine power, diesel generator power, and batteries capacity. The design parameters and their ranges of variation are listed in Table 3.

The results show that PSO and GA nearly give the same results. The difference between results of PSO and GA algorithms is less than $3 \%$. It is observed that PSO algorithm has higher rate of convergence and requires less computational effort during the optimization process.

The results of PSO algorithm optimizations are presented in Table 4. Figures 6 and 7, respectively, show the PV panels, the wind turbine, and the diesel generator power for an optimal configuration of the hybrid system in the cases under study.

As shown in Figure 6, the values of PV power for optimal configurations in Langroud, Meshkinshahr, and Bojnord are low. The optimal configuration system size depends on the available wind and solar potential at the site. These regions are situated in

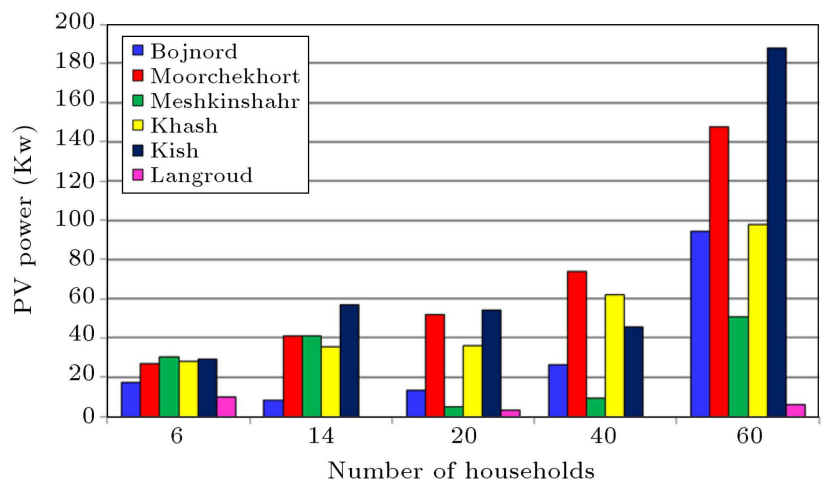

Figure 6. PV power in optimized hybrid systems configuration.

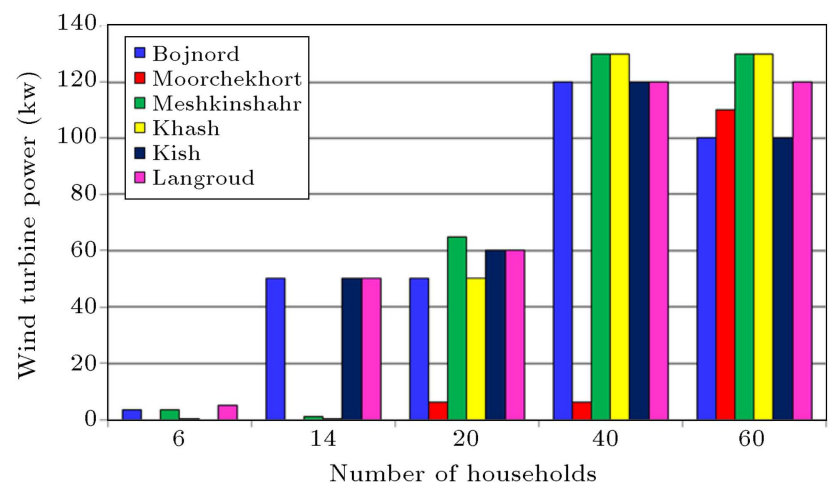

Figure 7. Wind turbine power in optimized hybrid systems configuration.

northern Iran and have a low solar potential. They receive less solar radiation than lower latitudes in central and southern regions. In addition, the low clear index in Langroud leads to the lowest PV power in hybrid systems in this region.

As shown in Figure 7 , in the villages with 6 and 14 households, the wind turbine has not been selected (or the wind turbine power in comparison with $\mathrm{PV}$ power is negligible). This is because the capital cost to produce a kw power in small wind turbine is

Table 3. Design parameters and their ranges of variation.

\begin{tabular}{ccccccc}
\hline \multirow{2}{*}{ Variables } & & \multicolumn{5}{c}{ Number of households } \\
\cline { 3 - 7 } & & $\mathbf{6}$ & $\mathbf{1 4}$ & $\mathbf{2 0}$ & $\mathbf{4 0}$ & $\mathbf{6 0}$ \\
\hline \multirow{2}{*}{ PV power (kw) } & From & 0 & 0 & 0 & 0 & 0 \\
& To & 36 & 84 & 120 & 240 & 360 \\
& & & & & & \\
Wind turbine power (kw) & From & 0 & 0 & 0 & 0 & 0 \\
& To & 50 & 80 & 100 & 250 & 350 \\
Diesel generator power (kw) & From & 0 & 0 & 0 & 0 & 0 \\
& To & 20 & 55 & 65 & 150 & 175 \\
Battery capacity (Ah) & From & 0 & 0 & 0 & 0 & 0 \\
& To & 1100 & 2400 & 3500 & 6800 & 10200 \\
\hline
\end{tabular}


Table 4. Results of the optimizations.

\begin{tabular}{|c|c|c|c|c|c|c|c|c|}
\hline Region & $\begin{array}{c}\text { Number } \\
\text { of } \\
\text { households }\end{array}$ & $\begin{array}{c}\text { PV } \\
\text { power } \\
(\mathrm{kw})\end{array}$ & $\begin{array}{c}\text { Wind } \\
\text { turbine power } \\
(\mathrm{kw})\end{array}$ & $\begin{array}{c}\text { Diesel } \\
\text { generator } \\
\text { power (kw) }\end{array}$ & $\begin{array}{l}\text { Battery } \\
\text { capacity } \\
(\mathrm{Ah})\end{array}$ & $\begin{array}{c}\text { LCC of } \\
\text { system } \\
(\$) \\
\end{array}$ & $\begin{array}{c}\text { ALCC for } \\
\text { household } \\
(\$)\end{array}$ & $\begin{array}{c}\text { COE } \\
(\$ / k w h)\end{array}$ \\
\hline \multirow{5}{*}{ Bojnord } & 6 & 17.04 & 3.2 & 15 & 400 & 193306.41 & 1346.9 & 0.197 \\
\hline & 14 & 8.4 & 50 & 30 & 600 & 253108.18 & 755.82 & 0.111 \\
\hline & 20 & 13.2 & 50 & 55 & 1300 & 356114.59 & 744.39 & 0.109 \\
\hline & 40 & 26.64 & 120 & 100 & 2400 & 625788.79 & 654.04 & 0.096 \\
\hline & 60 & 94.32 & 100 & 140 & 3100 & 1060134.58 & 738.67 & 0.108 \\
\hline \multirow{5}{*}{ Moorchekhort } & 6 & 27.12 & 0 & 15 & 460 & 177279.16 & 1235.22 & 0.181 \\
\hline & 14 & 41.28 & 0 & 55 & 1000 & 389866.51 & 1164.2 & 0.17 \\
\hline & 20 & 52.08 & 6 & 55 & 1400 & 505281.03 & 1056.19 & 0.155 \\
\hline & 40 & 73.92 & 6 & 100 & 2200 & 920124.94 & 961.67 & 0.141 \\
\hline & 60 & 147.84 & 110 & 175 & 3900 & 1374510.77 & 957.71 & 0.14 \\
\hline \multirow{5}{*}{ Meshkinshahr } & 6 & 30.48 & 3.2 & 5 & 900 & 181881.24 & 1267.29 & 0.186 \\
\hline & 14 & 41.28 & 1 & 55 & 1200 & 416824.99 & 1244.7 & 0.182 \\
\hline & 20 & 4.56 & 65 & 55 & 1200 & 377009.87 & 788.06 & 0.115 \\
\hline & 40 & 9.6 & 130 & 100 & 2600 & 730005.78 & 762.97 & 0.112 \\
\hline & 60 & 50.88 & 130 & 175 & 4000 & 1095531.22 & 763.33 & 0.112 \\
\hline \multirow{5}{*}{ Khash } & 6 & 28.08 & 0.1 & 15 & 500 & 188740.37 & 1315.08 & 0.193 \\
\hline & 14 & 35.52 & 0.3 & 55 & 1200 & 408989.97 & 1221.3 & 0.179 \\
\hline & 20 & 36 & 50 & 55 & 1900 & 513894.6 & 1074.19 & 0.157 \\
\hline & 40 & 61.92 & 130 & 140 & 3000 & 935042.15 & 977.26 & 0.143 \\
\hline & 60 & 97.68 & 130 & 150 & 3900 & 1360184.93 & 947.73 & 0.139 \\
\hline \multirow{5}{*}{ Kish } & 6 & 29.04 & 0 & 15 & 600 & 197827.64 & 1378.4 & 0.202 \\
\hline & 14 & 57.12 & 50 & 40 & 1000 & 386591.39 & 1154.42 & 0.169 \\
\hline & 20 & 54.24 & 60 & 55 & 1400 & 494842.28 & 1034.37 & 0.151 \\
\hline & 40 & 45.36 & 120 & 100 & 2300 & 911600.51 & 952.76 & 0.14 \\
\hline & 60 & 187.68 & 100 & 175 & 4000 & 1449487.25 & 1009.95 & 0.148 \\
\hline \multirow{5}{*}{ Langroud } & 6 & 10.08 & 5 & 20 & 500 & 204431.14 & 1424.41 & 0.209 \\
\hline & 14 & 0 & 50 & 40 & 1000 & 305106.57 & 911.09 & 0.133 \\
\hline & 20 & 2.88 & 60 & 55 & 1400 & 386513.87 & 807.93 & 0.118 \\
\hline & 40 & 0 & 120 & 140 & 2800 & 724085.83 & 756.78 & 0.111 \\
\hline & 60 & 5.76 & 120 & 150 & 4000 & 1091238.2 & 760.34 & 0.111 \\
\hline
\end{tabular}

considerably more than that in medium (and large) wind turbine. Generally, the wind turbine power is lowest in Moorchekhort. This result was predictable because of the low wind speed in this region.

Figure 8 shows that the diesel generator power for optimal configuration at a specified load does not vary in the cases under study. The results show that the diesel generator power is able to supply the maximum load of the villages.

\subsection{Power production}

The hourly power production of the simulated hybrid system generators on September 5 , in a village with

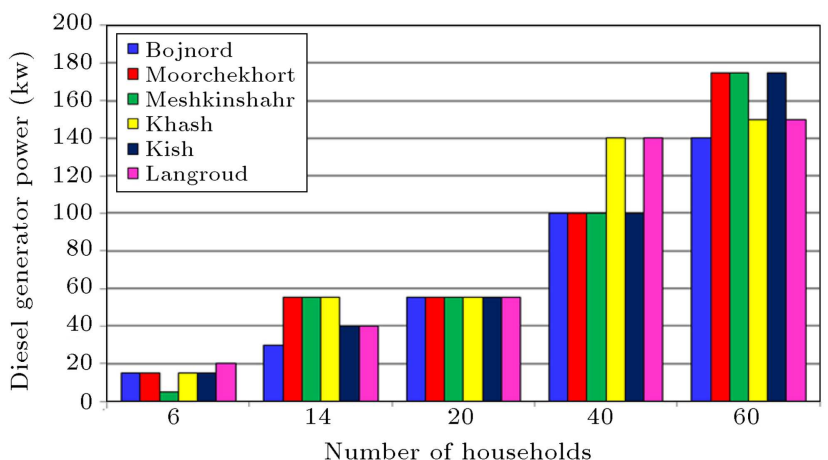

Figure 8. Diesel generator power in optimized hybrid systems configuration. 


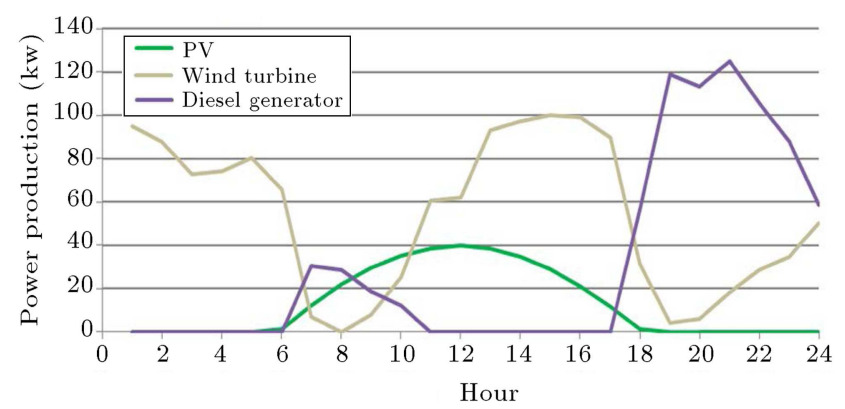

Figure 9. Hourly energy production of hybrid system generators on September 5, in a village with 60 households situated in Meshkinshahr.

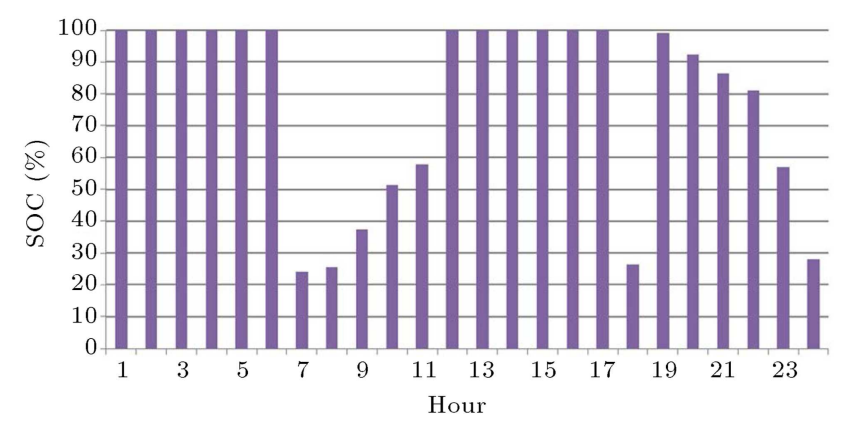

Figure 10. Charge state of batteries on September 5, in a village with 60 households situated in Meshkinshahr.

60 households situated in Meshkinshahr, is depicted in Figure 9. During morning and the first half of the night, the loads are more than the power production of renewable generators; thus, the diesel generator is switched on to supply load and batteries. The charge state of the batteries (SOC) is shown in Figure 10. As can be seen, the excess electricity produced by the renewable and diesel generators was used to charge the batteries.

\subsection{Economic analysis}

The Annualized Life Cycle Cost (ALCC) of a hybrid system for each household and the cost of electricity for the studied cases are presented in Figures 11 and 12, respectively.

As shown in Figure 11, the annualized cost of family depends on the village population and its location. Generally, it is found that the annualized family cost decreases as the load size (population of village) increases. For example, in Langroud, the annualized cost of the system per family in a village with 6 households is 1.9 times more than that in a village with 60 families. In this study, the minimum annualized cost of the hybrid system was found in the 40 households loads in Bojnord (654 \$/year). The COE of this case was $0.096(\$ / \mathrm{kwh})$.

The cost of electricity generation from nonrenewable resources in Iran is $0.0496(\$ / \mathrm{kwh})$. Due to governmental subsidies, the residential electricity tariff has fallen to 0.028 ( $\$ / \mathrm{kwh})$ [43]. Thus, based on

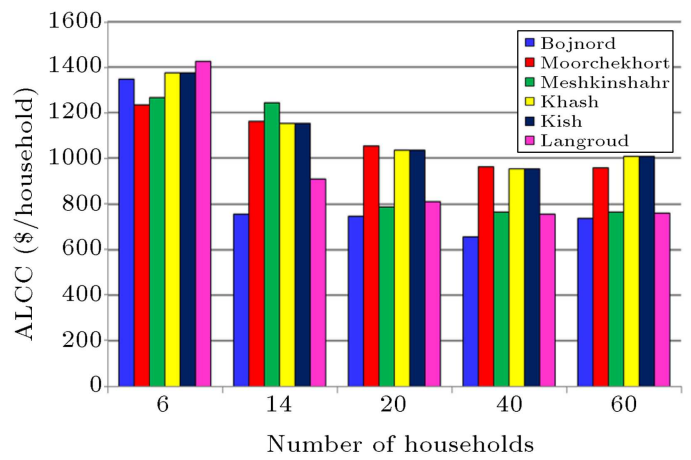

Figure 11. Annualized life cycle cost of hybrid systems for each household.

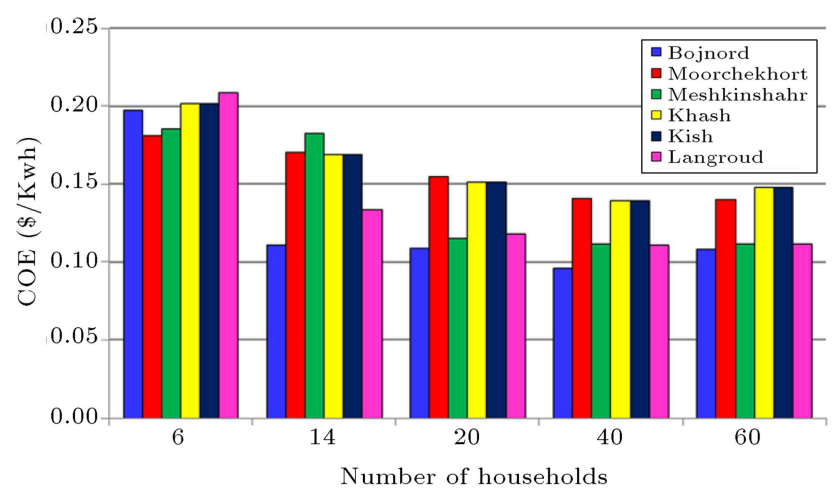

Figure 12. Cost of energy in cases under study.

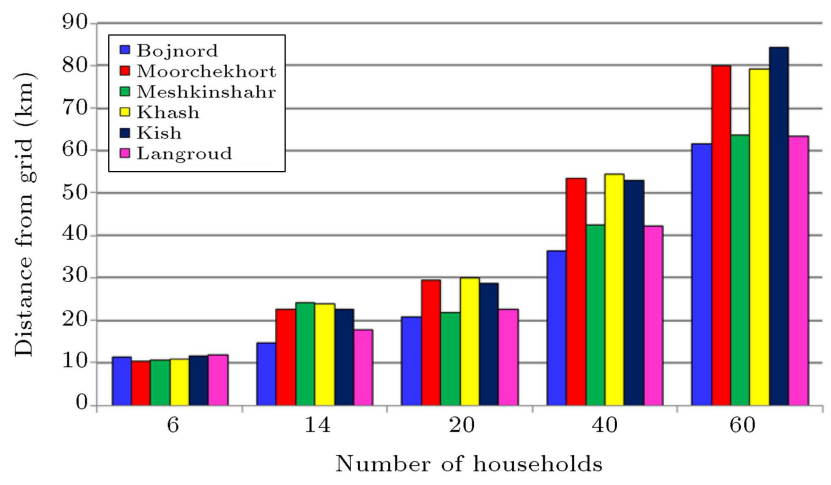

Figure 13. The minimum distance of village from grid, where implementation of hybrid system is more economic than constructing transmission lines.

the load profile represented in Figure 5, the household annual cost of buying electricity from the grid is 260 (\$/year).

In Iran, the average costs for constructing power transmission lines in mountain and plain regions are 19,200 and $15,200(\$ / \mathrm{km})$, respectively [44]. Due to this fact, the distance of the village from the electricity grid is an important parameter in choosing between a hybrid system and constructing transmission lines for rural electricity supply.

Figure 13 shows the minimum distance of the village from the grid, where it becomes more economically beneficial to implement a hybrid system than 
to construct transmission lines. As shown in this figure, this distance is related directly to the village population. For example, if the grid distance from a village with 6 households in Moorchekhort is more than $10 \mathrm{~km}$, the implementation of hybrid system will be economically feasible; but for a village with 60 households, this distance should be more than $80 \mathrm{~km}$. It should be noted that most remote villages in Iran are more distant from the grid than the values depicted in Figure 13. This means that the implementation of a hybrid system for off-grid remote villages in Iran is more economic than connecting the village to the electricity grid.

\section{Conclusion}

The hybrid of PV-wind-diesel power with battery storage systems was modeled and optimized in villages with $6,14,20,40$, and 60 households located in six regions of Iran with different climates. The developed methodology is based on the use of long-term wind speed data. The design parameters (decision variables) were PV power, wind turbine power, diesel generator power, and battery storage capacity. In the presented optimization problem, the total annual cost was the objective function.

Obtained results clearly show the high impact of the site energetic potential (wind and solar radiation) as well as the load profile on the optimal hybrid system constitution and the related cost of the hybrid system. The results also show that the power of diesel generator for optimal configurations at specified load does not vary in the cases under study.

Generally, it can be found that the annualized family cost decreases as the load size (population of village) increases. The $\mathrm{COE}$ for optimized systems varies between $0.096-0.209(\$ / \mathrm{kwh})$, whereas, the cost of electricity generation from non-renewable resources in Iran is much less than these values.

Due to the cost of constructing power transmission lines, the minimum distance of village from the grid, where the implementation of a hybrid system becomes more economical than constructing transmission lines, is calculated. Since the distance of the most remote villages from the grid is more than these values in Iran, the implementation of hybrid systems for off-grid remote villages in Iran is more economical than connecting the villages to the electricity grid.

\section{References}

1. Johansson, T.B., Patwardhan, A.P., Nakićenović, N. and Gomez-Echeverri, L., Global Energy AssessmentToward a Sustainable Future, Cambridge University Press, Cambridge, UK (2012).
2. World Energy Outlook, International Energy Agency (2012).

3. Yamegueu, D., Azoumah, Y., Py, X. and Zongo, N. "Experimental study of electricity generation by solar PV/diesel hybrid systems without battery storage for off-grid areas", Renewable Energy, 36, pp. 1780-1787 (2011).

4. Kaabeche, A., Belhamel, M. and Ibtiouen, R. "Sizing optimization of grid-independent hybrid photovoltaic/wind power generation system", Energy, 36(2), pp. 1214-1222 (2011).

5. Ai, B., Yang, H., Shen, H. and Liao, X. "Computeraided design of $\mathrm{PV} /$ wind hybrid system", Renewable Energy, 28(10), pp. 1491-1512 (2003).

6. Basbous, T., Younes, R., Ilinca, A. and Perron, J. "Optimal management of compressed air energy storage in a hybrid wind-pneumatic-diesel system for remote area's power generation", Energy, 84, pp. 267278 (2015).

7. Khalilnejad, A. and Riahy, G.H. "A hybrid windPV system performance investigation for the purpose of maximum hydrogen production and storage using advanced alkaline electrolyzer", Energy Conversion and Management, 80, pp. 398-406 (2014).

8. Diaf, S., Belhamel, M., Haddadi, M. and Louche, A. "Technical and economic assessment of hybrid photovoltaic/wind system with battery storage in Corsica island", Energy Policy, 36(2), pp. 743-754 (2008).

9. Dufo-López, R. and Bernal-Agustín, J.L. "Design and control strategies of PV-Diesel systems using genetic algorithms", Solar Energy, 79, pp. 33-46 (2005).

10. Tamer Khatiba, A.M., Sopianb, K. and Mahmoudc. M. "Optimal sizing of building integrated hybrid $\mathrm{PV} /$ diesel generator system for zero load rejection for Malaysia", Energy and Buildings, 43, pp. 3430-3435 (2011).

11. Yap, W.K. and Karri, V. "An off-grid hybrid PV/diesel model as a planning and design tool, incorporating dynamic and ANN modelling techniques", Renewable Energy, 78, pp. 42-50 (2015).

12. Suresh Kumar, U. and Manoharan, P.S. "Economic analysis of hybrid power systems (PV/diesel) in different climatic zones of Tamil Nadu", Energy Conversion and Management, 80, pp. 469-476 (2014).

13. Ramli, M.A.M., Hiendro, A. and Twaha, S. "Economic analysis of PV/diesel hybrid system with flywheel energy storage", Renewable Energy, 78, pp. 398-405 (2015).

14. Kamal, E., Koutb, M., Sobaih, A.A. and Abozalam, B. "An intelligent maximum power extraction algorithm for hybrid wind-diesel-storage system", International Journal of Electrical Power \& Energy Systems, 32(3), pp. 170-177 (2010).

15. Hu, Y. and Solana, P. "Optimization of a hybrid 
diesel-wind generation plant with operational options", Renewable Energy, 51, pp. 364-372 (2013).

16. Sebastián R. "Reverse power management in a wind diesel system with a battery energy storage", International Journal of Electrical Power \& Energy Systems, 44(1), pp. 160-167 (2013).

17. Essalaimeh, S., Al-Salaymeh, A. and Abdullat, Y. "Electrical production for domestic and industrial applications using hybrid PV-wind system", Energy Conversion and Management, 65, pp. 736-743 (2013).

18. Li, C., Ge, X., Zheng, Y., et al. "Techno-economic feasibility study of autonomous hybrid wind/PV/battery power system for a household in Urumqi, China", Energy, 55, pp. 263-272 (2013).

19. Benson, C.L. and Magee, C.L. "On improvement rates for renewable energy technologies: Solar PV, wind turbines, capacitors, and batteries", Renewable Energy, 68, pp. 745-751 (2014).

20. Bhattacharjee, S. and Acharya, S. "PV-wind hybrid power option for a low wind topography", Energy Conversion and Management, 89, pp. 942-954 (2015).

21. Maleki, A., Ameri, M. and Keynia, F. "Scrutiny of multifarious particle swarm optimization for finding the optimal size of a PV/wind/battery hybrid system", Renewable Energy, 80, pp. 552-563 (2015).

22. Dufo-López, R., Bernal-Agustín, J.L., Yusta-Loyo, J.M., et al. "Multi-objective optimization minimizing cost and life cycle emissions of stand-alone PV-winddiesel systems with batteries storage", Applied Energy, 88(11), pp. 4033-4041 (2011).

23. Abdel-Karim Daud, M.S.I. "Design of isolated hybrid systems minimizing costs and pollutant emissions", Renewable Energy, 44, pp. 215-224 (2012).

24. Merei, G., Berger, C. and Sauer, D.U. "Optimization of an off-grid hybrid PV-wind-diesel system with different battery technologies using genetic algorithm", Solar Energy, 97, pp. 460-473 (2013).

25. Maheri, A. "Multi-objective design optimisation of standalone hybrid wind-PV-diesel systems under uncertainties", Renewable Energy, 66, pp. 650-661 (2014).

26. Shin, Y., Koo, W.Y., Kim, T.H., Jung, S. and Kim, H. "Capacity design and operation planning of a hybrid PV-wind-battery-diesel power generation system in the case of Deokjeok island", Applied Thermal Engineering, 89, pp. 514-525 (2015).

27. Malheiro, A., Castro, P.M., Lima, R.M. and Estanqueiro, A. "Integrated sizing and scheduling of wind/PV/diesel/battery isolated systems", Renewable Energy, 83, pp. 646-657 (2015).

28. Deshmukh, M. and Deshmukh, S. "Modeling of hybrid renewable energy systems", Renewable and Sustainable Energy Reviews, 12(1), pp. 235-249 (2008).
29. Dufo-López, R. and Bernal-Agustín, J.L. "Influence of mathematical models in design of PV-Diesel systems", Energy Conversion and Management, 49(4), pp. 820831 (2008).

30. Dekker, J., Nthontho, M., Chowdhury, S. and Chowdhury, S.P. "Economic analysis of PV/diesel hybrid power systems in different climatic zones of South Africa", International Journal of Electrical Power \& Energy Systems, 40(1), pp. 104-112 (2012).

31. Heinrich, H., Photovoltaics System Design and Practice, Wiley (2012).

32. Beckman, W. Solar Engineering of Thermal Processes, John Willey \& Sons, New York (1991).

33. Koutroulis, E., Kolokotsa, D., Potirakis, A. and Kalaitzakis, K. "Methodology for optimal sizing of stand-alone photovoltaic/wind-generator systems using genetic algorithms", Solar Energy, 80(9), pp. 1072 1088 (2006).

34. Manwell, J.F., McGowan, J.G. and Rogers, A.L., Wind Energy Explained: Theory, Design and Application, 2nd, Ed., John Wiley \& Sons (2010).

35. Johnson, G.L., Wind Energy Systems, Manhattan University Reprints (2006).

36. Wind Atlas of Iran, Renewable energy organization of Iran, Available at: http://www.suna.org.ir/ (2014).

37. Hajabdollahi, Z., Hajabdollahi, F., Tehrani, M. and Hajabdollahi, H. "Thermo-economic environmental optimization of organic rankine cycle for diesel waste heat recovery", Energy, 63, pp. 142-151 (2013).

38. Bindner, H., Cronin, T., Lundsager, P., Manwell, J.F., Abdulwahid, U. and Baring-Gould, I., Lifetime Modelling of Lead Acid Batteries, Report Ris $\varnothing$ National Laboratory, Denmark (2005).

39. Notton, G., Lazarov, V. and Stoyanov, L. "Optimal sizing of a grid-connected PV system for various PV module technologies and inclinations, inverter efficiency characteristics and locations", Renewable Energy, 35(2), pp. 541-554 (2010).

40. Fuller, S. and Petersen, S., Life-Cycle Costing Manual For the Federal Energy Management Program, 1995 Edition, NIST Handbook (1996).

41. Kennedy, J. and Eberhart, R. "Particle swarm optimization", Proceedings of the IEEE International Conference on Neural Networks, Australia (1995).

42. Khorasaninejad, E. and Hajabdollahi, H. "Thermoeconomic and environmental optimization of solar assisted heat pump by using multi-objective particle swam algorithm", Energy, 72, pp. 680-690 (2014).

43. Iran's Balance Sheet, Iran Ministry of Energy, Tehran (2012).

44. Maslahati, V., Rural Electrification in 931 Villages, 
Iran Power Generation Transmission \& Distribution Management Co, Available at:

http://news.tavanir.org.ir/press (2014).

\section{Biographies}

Majid Sedghi received his BS degree in Mechanical Engineering from Iran University of Science and Technology in 2011, and MS degree in Mechanical Engineering from Sharif University of Technology, Iran, in 2013. He is currently a PhD student in Mechanical
Engineering at Isfahan University of Technology. His research interests include energy optimization, renewable energy, and heat transfer.

Siamak Kazemzadeh Hannani is currently professor of Mechanical Engineering at Sharif University of Technology, Iran. He received his doctorate in Mechanical Engineering from University of Lille in France, in 1996. His research interests involve energy system simulation, finite element, heat transfer, and turbulence modeling. 